REVIEW

\title{
A review of electromyographic activation levels, timing differences, and increased anterior cruciate ligament injury incidence in female athletes
}

\author{
T E Hewett, B T Zazulak, G D Myer, K R Ford
}

Br J Sports Med 2005;39:347-350. doi: 10.1136/bjsm.2005.018572

Deficits in dynamic neuromuscular control of the knee may contribute to the higher incidence of anterior cruciate ligament (ACL) injury in female athletes. There is evidence that neuromuscular training alters muscle firing patterns, as it decreases landing forces, improves balance, and reduces $\mathrm{ACL}$ injury incidence in female athletes. The purpose of this review is to summarise the evidence for altered muscular activation and timing relative to $\mathrm{ACL}$ injury risk in female athletes.

See end of article for authors' affiliations

.....................

Correspondence to: Dr Hewett, Cincinnati Children's Hospital, Sports Medicine Biodynamics Center, Cincinnati, OH 45229, USA; tim.hewett@ cchmc.org

Accepted

15 February 2005
D eficits in dynamic neuromuscular control of joint stability in all three axes of motion (proximal-distal, anterior-posterior, medial-lateral) along the entire lower extremity kinetic chain may contribute to differences in anterior cruciate ligament (ACL) injury rates between female and male athletes. Although the 4-6-fold higher incidence of ACL injuries in female athletes is well established, the underlying neuromuscular mechanisms that account for this are not completely delineated. The contribution of relative muscle activation levels to this important clinical dilemma is especially unclear. Lack of dynamic neuromuscular control of the knee (active restraint) is an important contributor to ACL (passive restraint to tibial translation) injury in female athletes. ${ }^{1}$ ACL injury occurs under conditions of high dynamic loading of the knee joint, when active muscular restraints do not adequately dampen joint loads and the passive restraints are subjected to increased loads. ${ }^{2}$ Decreased neuromuscular control of the joint may place increased stress the failure strength of the ligament. ${ }^{34}$ Neuromuscular recruitment patterns that compromise active joint restraints subject passive joint restraints to greater load, decrease dynamic knee stability, and increase risk of ACL injury. ${ }^{3}$

Female athletes display different neuromuscular strategies from male athletes. ${ }^{6-9}$ These sex differences in muscle recruitment and timing of muscle activation may affect dynamic knee stability. Neuromuscular preplanning allows feed forward recruitment of the musculature that controls knee joint positioning during landing and pivoting manoeuvres. ${ }^{10}$ Imbalanced or ineffectively timed neuromuscular firing may lead to limb positioning during athletic manoeuvres that puts the female ACL under increased strain and on the passive ligament structures that exceed risk of injury. ' Female subjects show greater dynamic lower extremity valgus (hip adduction and internal rotation, knee abduction, tibial external rotation, and possibly forefoot pronation). ${ }^{11-15}$

Altered neuromuscular timing and recruitment may lead to the aforementioned dynamic lower extremity valgus observed in women. ${ }^{11-15}$ Measures of dynamic valgus predict non-contact ACL injury risk in female athletes with an accuracy approaching 90\%.' Computer simulation modelling demonstrates that lower extremity valgus loads at the knee are high enough to rupture the ACL, whereas knee extension and anterior shear loads alone are not sufficient to rupture the ligament. ${ }^{15}$

Dynamic neuromuscular restraints to lower extremity joint motion include both feed forward and feedback motor control loops. ${ }^{16}$ Feed forward neuromuscular control, developed during previous movement, may activate muscles around the joint before excessive loading in order to absorb force and decrease stress on the ligaments. ${ }^{17}$ Feedback or reactive motor control strategies alter muscle activation in response to situations that load the lower extremity joints. ${ }^{18}$ Female subjects may display a longer latency period-that is, electromechanical delaybetween preparatory and reactive muscle activation. ${ }^{19}$ Preparatory muscle activity can stiffen joints before unexpected perturbations. ${ }^{17} 182021$ Neuromuscular training that reproduces loads similar to those encountered during competitive sports may assist in the development of both feed forward and reactive muscle activation strategies that protect the knee joint from excessive load. ${ }^{18^{19}}$ 21-24 Plyometric exercises subject the joint to rapid loads and can activate preparatory and feedback motor control loops by adaptation of the muscle stretch receptors. ${ }^{25}$ Balance and core stability exercises force the athlete to pretense the musculature and rapidly react to motion or perturbation.

If neuromuscular training can increase neuromuscular control of the joint and decrease knee and ACL injury risk, it is likely that the mechanisms underlying increased risk are neuromuscular in nature. Several prospective studies have shown that neuromuscular training has the potential to decrease knee injuries in general, and ACL injuries in particular, in athletes. ${ }^{26-30}$ Intensive short term neuromuscular

Abbreviations: $\mathrm{ACL}$, anterior cruciate ligament; $\mathrm{EMG}$, electromyographic 
training may induce a "neuromuscular spurt" that may otherwise be absent in adolescent females. ${ }^{13}{ }^{31-33}$ Training and strength differences may account for only a portion of the higher incidence of knee injury in female athletes, but lowering these high figures by even a small percentage could have a significant effect on the number of knee injuries in female athletes. Such training, if effectively implemented on a widespread basis, may help to considerably decrease the number of athletes injured each year.

The purpose of this review is to summarise the evidence for altered muscular activation and timing relative to ACL injury risk in female athletes.

\section{DIFFERENCES IN ELECTROMYOGRAPHIC (EMG) ACTIVATION LEVELS BETWEEN MALE AND FEMALE ATHLETES \\ Proximal}

Asymmetry of proximal muscle activation may alter the position of the knee during landing and cutting in female athletes. Decreased activation of the trunk and hip musculature may lead to lower extremity malalignment. Decreased activation of proximal stabilising muscles may lower load bearing capacity of the knee joint. Lephart et al ${ }^{16}$ report that female subjects have increased hip internal rotation during landing. Increased hip internal rotation and valgus may increase strain on the ACL. ${ }^{24}$ Zazulak et $a l^{8}$ report lower gluteal EMG activity in women than men during landing (figs 1 and 2). The proximal stabilising muscles, specifically the gluteals, control lower limb position, energy absorption, and function as powerful extensors, external rotators, and abductors of the hip during landing. ${ }^{83}$

Chimera $e t a^{36}$ evaluated the effects of plyometric training on muscle activation patterns during jump exercise and reported increased firing of the hip adductor muscles during the pre-landing phase. The experimental group showed greater preparatory adductor to abductor muscle activation. Hewett et $a l^{31}$ showed significant decreases in abduction/ adduction moments after plyometric training. These findings delineate the role of hip muscle activation in dynamic restraint and control of lower extremity alignment.

\section{Anterior-posterior}

Female athletes show increased activation of the quadriceps relative to the antagonistic hamstring musculature. ${ }^{14} 3137$ This disproportional recruitment of the vastus musculature increases anterior shear force at the low knee flexion angles that occur during high risk landing and pivoting

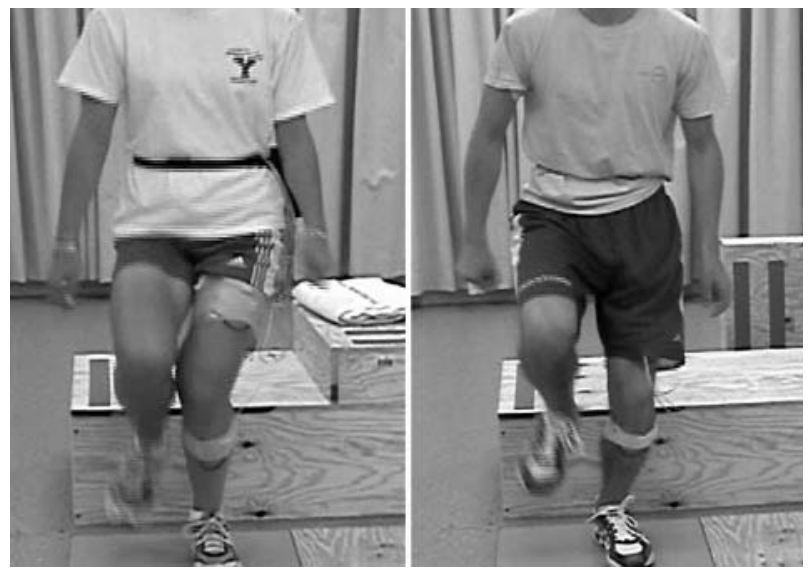

Figure 1 Visual representation of the landing manoeuvre tested in the study. Female (left) and male (right) subjects completing drop landings from $30.5 \mathrm{~cm}$ box heights. Patient consent was obtained for the publication of this figure.

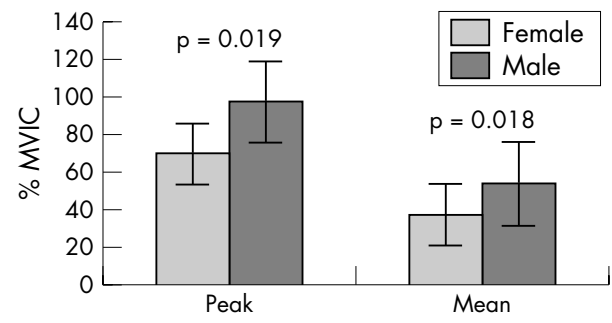

Figure 2 Gluteus maximus post-contact ensemble peak and mean electromyographic values in female and male subjects. Values are mean $\pm 1.96 \mathrm{SE}$. MVIC, Maximal voluntary isometric muscular contraction.

movements. ${ }^{94}$ The quadriceps, through the anterior pull of the patellar tendon on the tibia, contribute to ACL loading when knee flexion is less than $30^{\circ} .^{\circ} 38$ Muscular cocontraction compresses the joint, due in part to the concavity of the medial tibial plateau, which may protect the ACL against anterior drawer. ${ }^{39}$

Zazulak $e t a l^{8}$ reported greater peak quadriceps activity in female than male subjects (fig 3). Decreased balance in strength and recruitment of the flexor relative to the extensor musculature may put the ACL at greater risk. ${ }^{31}$ Adequate cocontraction of the knee flexors is needed to balance contraction of the quadriceps, compress the joint, and control high knee extension and abduction torques. ${ }^{31}$ Appropriate hamstrings recruitment may prevent the critical loading necessary to rupture the ACL during manoeuvres that place the athlete at risk of an injury.

\section{Medial-lateral}

Joint compression through muscular co-contraction allows valgus load to be carried by articular contact forces, protecting the ligaments. Decreased medial joint compression may limit passive resistance to dynamic knee valgus, predisposing the female knee to medial femoral condylar lift off and increased loads on the ACL. ${ }^{12}{ }^{40}{ }^{41}$ Rozzi et al ${ }^{6}$ reported that female athletes show a disproportionate (4 times greater) firing of their lateral hamstrings during landing. Myer et $a l^{9}$ showed a decreased ratio of medial to lateral quadriceps recruitment in female subjects (fig 4). The decreased ratio combined with unbalanced medial hamstrings recruitment may decrease control of coronal plane forces at the knee ${ }^{6440}$. Markolf et al ${ }^{34}$ showed that muscular contraction can decrease both the valgus and varus laxity of the knee threefold. A low ratio of medial to lateral quadriceps recruitment combined with increased lateral hamstring firing may compress the lateral joint, open the medial joint, and increase anterior shear force, which directly loads the ACL. ${ }^{634} 42$

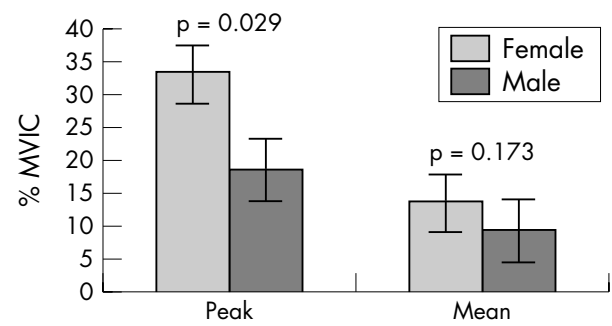

Figure 3 Rectus femoris pre-contact ensemble peak and mean electromyographic values in female and male subjects. Values are mean $\pm 1.96 \mathrm{SE}$. MVIC, Maximal voluntary isometric muscular contraction. 


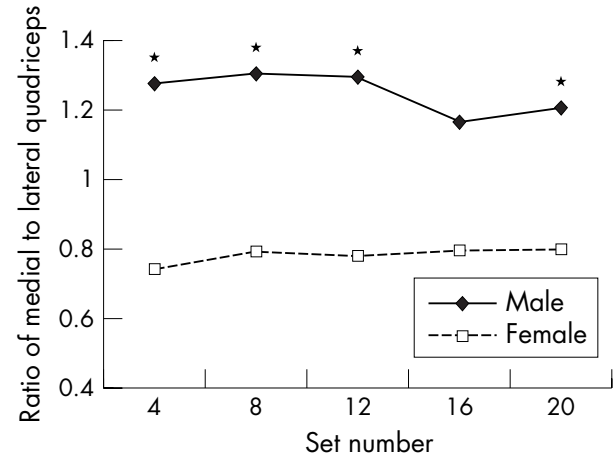

Figure 4 Root mean square ratio of medial to lateral quadriceps activation during performance of exercise sets. Female subjects displayed significantly decreased medial/lateral quadriceps activation. Reproduced, with permission, from Myer et al. ${ }^{9}$

\section{Distal}

Calf and ankle muscle recruitment may play a role in dynamic stabilisation of the knee joint. Besier et $a l^{10}$ reported selective activation of medial knee musculature, including the medial gastrocnemius, during sidestep tasks with valgus and external rotation moments. Nyland et $a l^{43}$ concluded that the gastrocnemius provided synergistic and compensatory dynamic knee stabilisation with quadriceps fatigue. ACL deficient female subjects showed decreased preactivation of the lateral gastrocnemius. ${ }^{44}$

Shultz et $a l^{45}$ evaluated the protective neuromuscular response and activation patterns to an imposed perturbation during weight bearing stance-that is, a sudden forward and either internal or external rotation moment of the trunk and femur. The gastrocnemius fired faster than the hamstring, which fired faster than the quadriceps. This activation pattern is similar to the postural response reported by Nashner, ${ }^{46}$ specifically a distal to proximal firing pattern, with the distal muscles preceding the proximal muscles by 10-15 milliseconds.

\section{TIMING OF MUSCLE FIRING}

EMG studies show sex related differences in the timing of muscle activation during athletic movement. ${ }^{6-10374748}$ Zazulak et $a l^{8}$ reported increased peak quadriceps activity in female subjects during the pre-contact phase of landing. Greater rectus femoris activity was observed in female than male subjects (fig 3). This increased activation of rectus femoris may increase strain on the ACL during landing. Increased quadriceps activity combined with decreased hamstring activity may decrease kinetic energy absorption during landing and may increase ground reaction forces and torques associated with ACL injury.

Wojtys $e t \mathrm{al}^{37}$ reported that female athletes have a slower response of hamstring activation to anterior stress on the ACL. Cowling and Steele ${ }^{48}$ reported sex differences in muscle activation strategies in the hamstrings musculature that contradict the findings of Wojtys et al. Male subjects were found to activate their semi-membranosis muscle later than female subjects in the pre-landing phase and reach peak activity sooner. ${ }^{48}$ Besier et $a l^{10}$ examined a sidestep cut at two different angles under both preplanned and unanticipated conditions. They found increased varus/valgus and internal/ external knee moments during unanticipated movements and suggested that there may be increased potential for noncontact knee injuries during unanticipated sport movements.

Lower extremity muscle activation during cutting may be different between preplanned and unanticipated conditions. ${ }^{47}$ Besier et $a l^{47}$ also reported that activation patterns during cutting manoeuvres are preplanned to counter loading in response to varus/valgus and internal/external rotation moments at the knee. The unanticipated sidestep condition was reported to increase muscle activation $10-25 \%$, with the greatest increase before initial contact. ${ }^{47}$ ACL injuries occur too quickly for reflexive or voluntary muscular activation. However, preactivation may reduce the probability of injuries caused by unexpected perturbations. The lower extremity musculature may be $40-80 \%$ activated at the time that the foot touches the ground. ${ }^{49}$

\section{SUMMARY AND CONCLUSIONS}

Differences are observed in male and female EMG firing patterns. Decreased neuromuscular control of the trunk and lower extremity in women may increase the potential for valgus lower extremity position and increased ACL injury risk. Identification of these neuromuscular imbalances has potential for both screening of high risk athletes and targeting interventions to specific deficits. Dynamic neuromuscular training can increase active knee stabilisation and decrease the incidence of ACL injury in the female athletic population. 26315051 Training may facilitate neuromuscular adaptations that provide increased joint stabilisation and muscular preactivation and reactive patterns that protect the athlete's ACL from increased loading..$^{50} 53$

In conclusion, there is evidence that neuromuscular training alters muscle firing patterns as it decreases landing forces, improves balance, and reduces ACL injury incidence in female athletes. Future approaches could be to use EMG analysis to assess the relative efficacy of these interventions in order to achieve the optimal effect in the most efficient manner possible. Selective combination of neuromuscular training components may provide additive effects, further reducing the risk of ACL injuries in female athletes. Additional research directions include the assessment of relative injury risk using mass neuromuscular screening. The development of screening and intervention protocols may lead to the reduction of ACL injury incidence in female athletes through the identification of the high risk female athlete subgroup that displays decreased hip and increased quadriceps muscle firing, and the correction of these neuromuscular control deficits.

\section{ACKNOWLEDGEMENTS}

We acknowledge funding support from National Institutes of Health Grant R01-AR049735-01Al (to TEH). We also acknowledge Patricia L Ponce, PT, MS, ATC, and Stephen J Straub, PhD, ATC, for assistance with the figures. We would also like to thank Tiffany Evans for her assistance with preparation of the manuscript.

\section{Authors' affiliations}

T E Hewett, G D Myer, K R Ford, Cincinnati Children's Hospital, Sports Medicine Biodynamics Center, Cincinnati, OH, USA

B T Zazulak, Department of Rehabilitation Services, Yale-New Haven Hospital, New Haven, CT, USA

Competing interests: none declared

Patient consent was obtained for the publication of figure 1 .

\section{REFERENCES}

1 Hewett TE, Myer GD, Ford KR, et al. Biomechanical measures of neuromuscular control and valgus loading of the knee predict $A C L$ injury risk in female athletes. Am J Sports Med. 2005;33: in press.

2 Beynnon BD, Fleming BC. Anterior cruciate ligament strain in-vivo: a review of previous work. J Biomech 1998;31:519-25.

3 Li G, Rudy TW, Sakane M, et al. The importance of quadriceps and hamstring muscle loading on knee kinematics and in-situ forces in the ACL. J Biomech 1999;32:395-400.

4 Markolf KL, Graff-Redford A, Amstutz HC. In vivo knee stability: a quantitative assessment using an instrumented clinical testing apparatus. J Bone Joint Surg [Am] 1978;60:664-74. 
5 Besier TF, Lloyd DG, Cochrane JL, et al. External loading of the knee joint during running and cutting maneuvers. Med Sci Sports Exerc 2001;33:1168-75.

6 Rozzi SL, Lephart SM, Gear WS, et al. Knee joint laxity and neuromuscular characteristics of male and female soccer and basketball players. Am J Sports Med 1999;27:312-19.

7 Woitys EM, Ashton-Miller JA, Huston $\amalg$. A gender-related difference in the contribution of the knee musculature to sagittal-plane shear stiffness in subjects with similar knee laxity. J Bone Joint Surg [Am] 2002;84:10-16.

8 Zazulak BT, Ponce P, Straub SJ, et al. Gender comparison of hip muscle activity during single-leg landing. J Orthop Sports Phys Ther 2005;35:in press.

9 Myer GD, Ford KR, Hewett T. The effects of gender on quadriceps muscle activation strategies during a maneuver that mimics a high $A C L$ injury risk position. J Electromyogr Kinesiol 2005; 15: in press.

10 Besier TF, Lloyd DG, Ackland TR, et al. Anticipatory effects on knee joint loading during running and cutting maneuvers. Med Sci Sports Exerc 2001;33:1176-81.

11 Chappell JD, Yu B, Kirkendall DT, et al. A comparison of knee kinetics between male and female recreational athletes in stop-jump tasks. Am J Sports Med 2002;30:261-7.

12 Ford KR, Myer GD, Hewett TE. Valgus knee motion during landing in high school female and male basketball players. Med Sci Sports Exerc 2003;35:1745-50.

13 Hewett TE, Myer GD, Ford KR. Decrease in neuromuscular control about the knee with maturation in female athletes. J Bone Joint Surg [Am] 2004;86:1601-8

14 Malinzak RA, Colby SM, Kirkendall DT, et al. A comparison of knee joint motion patterns between men and women in selected athletic tasks. Clin Biomech $2001 ; 16: 438-45$.

15 McLean SG, Huang X, Su A, et al. Sagittal plane biomechanics cannot injure the ACL during sidestep cutting. Clin Biomech 2004;19:828-38.

16 Lephart SM, Ferris CM, Riemann BL, et al. Gender differences in strength and lower extremity kinematics during landing. Clin Orthop 2002;401:162-9.

17 Beard DJ, Kyberd PJ, Fergusson CM, et al. Proprioception after rupture of the anterior cruciate ligament. An objective indication of the need for surgery? $J$ Bone Joint Surg [Br] 1993;75:31 1-15.

18 Dyhre-Poulsen P, Simonsen EB, Voigt M. Dynamic control of muscle stiffness and $\mathrm{H}$ reflex modulation during hopping and jumping in man. J Physiol 1991;437:287-304

19 Winter EM, Brookes FB. Electromechanical response times and muscle elasticity in men and women. Eur J Appl Physiol Occup Physiol 1991:63:124-8.

20 Woitys EM, Huston $\amalg$. Neuromuscular performance in normal and anterior cruciate ligament-deficient lower extremities. Am J Sports Med 1994;22:89-104.

21 Dietz V, Noth J, Schmidtbleicher D. Interaction between pre-activity and stretch reflex in human triceps brachii during landing from forward falls. J Physiol 1981;311:113-25.

22 Dunn TG, Gillig SE, Ponsor SE, et al. The learning process in biofeedback: is it feed-forward or feedback? Biofeedback Self Regul 1986;11:143-56.

23 Greenwood R, Hopkins A. Landing from an unexpected fall and a voluntary step. Brain 1976:99:375-86.

24 Thompson HW, McKinley PA. Landing from a jump: the role of vision when landing from known and unknown heights. Neuroreport 1995;6:581-4.

25 Wilk KE, Voight ML, Keirns MA, et al. Stretch-shortening drills for the upper extremities: theory and clinical application. J Orthop Sports Phys Ther 1993; 17:225-39.

26 Hewett TE, Lindenfeld TN, Riccobene JV, et al. The effect of neuromuscular training on the incidence of knee injury in female athletes. A prospective study. Am J Sports Med 1999;27:699-706.

27 Wedderkopp N, Kaltoft M, Lundgaard B, et al. Prevention of injuries in young female players in European team handball. A prospective intervention study. Scand J Med Sci Sports 1999;9:41-7.

28 Heidt RS Jr, Sweeterman LM, Carlonas RL, et al. Avoidance of soccer injuries with preseason conditioning. Am J Sports Med 2000;28:659-62.

29 Soderman K, Werner S, Pietila T, et al. Balance board training: prevention of traumatic injuries of the lower extremities in female soccer players? A prospective randomized intervention study. Knee Surg Sports Traumatol Arthrosc 2000;8:356-63.
30 Mandelbaum BR, Silvers $\mathrm{HJ}$, Watanabe $\mathrm{D}$, et al. Effectiveness of a neuromuscular and proprioceptive training program in preventing the incidence of $A C L$ injuries in female athletes: two-year follow up. Am J Sports Med, 2005; in press.

31 Hewett TE, Stroupe AL, Nance TA, et al. Plyometric training in female athletes. Decreased impact forces and increased hamstring torques. Am J Sports Med 1996;24:765-73

32 Myer GD, Ford KR, Divine JG, et al. Specialized dynamic neuromuscular training can be utilized to induce neuromuscular spurt in female athletes. Med Sci Sports Exerc 2004;36:343-4.

33 Myer GD, Ford KR, Hewett TE. Methodological approaches and rationale for training to prevent anterior cruciate ligament injuries in female athletes. Scand J Med Sci Sports 2004;14:275-85.

34 Markolf KL, Burchfield DM, Shapiro MM, et al. Combined knee loading states that generate high anterior cruciate ligament forces. J Orthop Res 1995; 13:930-5.

35 Delp SL, Hess WE, Hungerford DS, et al. Variation of rotation moment arms with hip flexion. J Biomech 1999;32:493-501.

36 Chimera NJ, Swanik KA, Swanik CB, et al. Effects of plyometric training on muscle-activation strategies and performance in female athletes. J Athl Train 2004;39:24-31.

37 Woitys EM, Huston $\amalg$, Taylor PD, et al. Neuromuscular adaptations in isokinetic, isotonic, and agility training programs. Am J Sports Med 1996;24:187-92

38 Renstrom P, Arms SW, Stanwyck TS, et al. Strain within the anterior cruciate ligament during hamstring and quadriceps activity. Am J Sports Med $1986 ; 14: 83-7$.

39 Imran A, O'Connor JJ. Theoretical estimates of cruciate ligament forces: effects of tibial surface geometry and ligament orientations. Proc Inst Mech Eng $[H]$ 1997;21 1:425-39.

40 Kim AW, Rosen AM, Brander VA, et al. Selective muscle activation following electrical stimulation of the collateral ligaments of the human knee joint. Arch Phys Med Rehabil 1995;76:750-7

41 Lloyd DG. Rationale for training programs to reduce anterior cruciate ligament injuries in Australian football. J Orthop Sports Phys Ther 2001;31:645-54; discussion 661.

42 Sell T, Ferris CM, Abt JP, et al. Predictors of anterior tibia shear force during a vertical stop-jump. J Orthop Sports Phys Ther 2004;34(1-PL 14).

43 Nyland JA, Caborn DN, Shapiro R, et al. Fatigue after eccentric quadriceps femoris work produces earlier gastrocnemius and delayed quadriceps femoris activation during crossover cutting among normal athletic women. Knee Surg Sports Traumatol Arthrosc 1997;5:162-7.

44 DeMont RG, Lephart SM, Giraldo JL, et al. Muscle preactivity of anterior cruciate ligament-deficient and -reconstructed females during functional activities. J Athl Train 1999;34:115-20.

45 Shultz SJ, Perrin DH, Adams JM, et al. Assessment of neuromuscular response characteristics at the knee following a functional perturbation. J Electromyogr Kinesiol 2000;10:159-70.

46 Nashner LM. Fixed patterns of rapid postural responses among leg muscles during stance. Exp Brain Res 1977;30:13-24.

47 Besier TF, Lloyd DG, Ackland TR. Muscle activation strategies at the knee during running and cutting maneuvers. Med Sci Sports Exerc 2003:35: 119-27.

48 Cowling EJ, Steele JR. Is lower limb muscle synchrony during landing affected by landing? J Electromyogr Kinesiol 2001;11:263-8.

49 Neptune RR, Wright IC, van den Bogert AJ. Muscle coordination and function during cutting movements. Med Sci Sports Exerc 1999:31:294-302.

50 Myer GD, Ford KR, Palumbo JP, et al. Comprehensive neuromuscular training improves both performance and lower extremity biomechanics in female athletes. J Strength Cond Res 2005; 19:51-60.

51 Myklebust G, Engebretsen L, Braekken IH, et al. Prevention of anterior cruciate ligament injuries in female team handball players: a prospective intervention study over three seasons. Clin J Sport Med 2003;13:71-8.

52 Lloyd DG, Buchanan TS. A model of load sharing between muscles and soft tissues at the human knee during static tasks. J Biomech Eng 1996;118:367-76.

53 Solomonow M, Krogsgaard M. Sensorimotor control of knee stability. A review. Scand J Med Sci Sports 2001;11:64-80 